\title{
Pharmaceutical care journey: Final-year pharmacy students' experiences of the hospital-based clinical pharmacy clerkship programme in north- east Nigeria
}

\author{
Roland N Okoro, John David Ohieku, Sani Ibn Yakubu \\ University of Maiduguri, Nigeria
}

\author{
Keywords \\ Clinical Pharmacy Clerkship Experiential \\ Learning \\ Pharmacy Students \\ Ward Round \\ Nigeria
}

Correspondence
Roland N. Okoro
Department of Clinical Pharmacy and
Pharmacy Administration
University of Maiduguri
Nigeria
orolandn@gmail.com

\begin{abstract}
Context: Pharmacy students need practical clinical knowledge and skills to be able to provide effective pharmaceutical care after graduation. To achieve this, pharmacy students need an effective clinical clerkship programme. Aims: To assess final-year pharmacy students' preparedness, expectations, and experiences of a hospital-based clinical pharmacy clerkship (CPC) programme. Methods: A pre-post, qualitative study involving focus groups was conducted in a Nigerian university. All final-year Bachelor of Pharmacy (B.Pharm.) students of the 2019 academic year (October 2018 to June 2019) who enrolled for the CPC course participated in the study. Results: The prevailing themes identified were: theme one (level of preparedness and hospital environment), theme two (integration of knowledge and application to patient care), theme three (inter-professional relationships and professional identity), and theme four (challenges and recommendations). Conclusions: This study shows that B.Pharm. students exhibited a high level of preparedness and expectations prior to commencement of the CPC. They also had unsatisfactory experiences during the CPC due to various challenges and unmet expectations mainly in terms of inter-professional relationships and the role of pharmacists in the healthcare team.
\end{abstract}

\section{Introduction}

Clinical pharmacy practice is well established and practiced in developed countries like the United States of America (U.S.A.), United Kingdom (U.K.), Australia, and Canada (Falade, 2011; Karim \& Noott, 2011; Carter, 2016; Lam, 2018). In accordance with global best pharmacy practice, developing countries like China, India, Pakistan, and Saudi Arabia have modified their pharmacy education to a more patient-centred curriculum. This aims to emphasise the need to provide more clinical knowledge than is currently included in education and training in addition to industrial knowledge to pharmacists (Asiri,
2011; Bhagavathula et al., 2014; CPU, 2015). In Nigeria, a new pharmacy programme (Doctor of Pharmacy) was approved in 2016 by the National Universities Commission (NUC) with the objective of training patient-centred pharmacists by extending the five-year undergraduate Bachelor of Pharmacy (B.Pharm.) programme to a six-year Doctor of Pharmacy (Pharm.D.) programme with an extended clinical pharmacy clerkship (CPC) syllabus (NUC, 2018).

The Faculty of Pharmacy at the University of Maiduguri in Nigeria currently provides a five-year B.Pharm. programme. The B.Pharm. curriculum of this university 
consists of mainly basic sciences in the first-year and pharmaceutical sciences during the remaining years. Before the students start their CPC, they have completed a six-month externship (Students Industrial Work Experience Scheme (SIWES)) in a hospital and/or community pharmacy during two long vacations in earlier study years. The over-arching objective of this programme is to prepare students for the real-world work situation for the first time. In addition, it provides them with an opportunity to apply their theoretical knowledge in real work situations, thereby bridging the gap between theory and practice. The B.Pharm. CPC course is a four-credit unit course that requires final-year pharmacy students to spend up to ten weeks in the hospital's wards during the second semester only. The Pharm.D. CPC courses consist of three-credit courses taken during the second semester of the fifth-year, and seven- and eight-credit courses taken during the first and second semester of the sixth-year (final-year), respectively. In each occasion, students are also required to spend up to ten weeks in the hospital's wards. The main objective of this experiential learning programme is to expose students to direct interaction with patients, other healthcare professionals, and their students. In addition, the programme aims to build confidence in pharmacy students and encourage them to become more involved in patient-centred pharmacy practice. The overall objective of this course is for the students to develop a rational, evidence-based understanding of the approach to prescribing, the use of drugs, and the achievement of positive optimal health outcomes within a realistic economic expenditure from drug therapy. An overview of the B.Pharm. curriculum of the University of Maiduguri is presented in Table I (Unimaid, 2016).

The students on clerkship are expected to be guided in the wards by hospital-based pharmacist preceptors and supervised and evaluated by university tutors. However, due to the absence of pharmacists from the wards and lack of hospital-based preceptors at both clerkship sites of the Faculty of Pharmacy of the University of Maiduguri, the university tutors usually organise a one and a half hour early morning case preview/review session for the students at the hospital premises before they proceed to the wards. These students are placed with physicians and medical students on wards (including cardiology, nephrology, neurology, gastroenterology, infectious diseases, endocrinology, and pulmonology) of a university teaching hospital and of a neuropsychiatry hospital (psychiatry). Students spend three days a week (four hours per day) and rotate every two weeks through the units.

The design of the CPC course of both Nigerian B.Pharm. and Pharm.D. programmes is quite different from that of $B$.
Pharm. programmes of some schools in Ethiopia (Tsega et al., 2015) and the professional Pharm.D. of many schools in the U.S.A. (ACPE, 2016) and Saudi Arabia (Asiri, 2011; KFU, 2014; Moustafa, 2014) where the entire final-year is allocated to practice experience in the hospital and/or community settings.

Including a hospital-based experiential learning programme as a critical component of pharmacy education has not been without challenges. Poor planning and no clear identification of duties and responsibilities of the universities, students, and preceptors in the workplace were reported in Australia (Owen \& Stupans, 2009). Similarly, inadequate integration of theory and practice was identified in Finland (Katajavuori et al., 2009), logistics problems in the U.K. (Sosabowski \& Gard, 2008), and a lack of clinical pharmacists to teach the students in the wards were reported in South Africa (McCartney \& Boschmans, 2018). A disconnect between classroom theory and real-world practice was also identified more locally to this study in Nigeria (Abdu-aguye et al., 2019). Other barriers identified were the shortness of the clerkship duration, and disconnect between didactic and practical training, noted in China (Lai et al., 2010; Meng et al., 2017). In Pakistan, issues were raised due to pharmacy students' poor preparedness for practice in relation to knowledge of workplace ethics and communication difficulties between pharmacy students and other healthcare professionals. A lack of academic and clinical training capacity in a number of institutions and inadequate established hospital pharmacy services were also reported as barriers to delivering effective clerkship training (Al-Worafi, 2014; Abbas, 2015). A lack of supervisors in Iran (Eslami et al., 2014) as well as the lack of clerkship training sites in established public and private hospitals and health centres in Saudi Arabia has also been reported (Moustafa, 2014). This literature indicates that there are multiple barriers to developing effective workplace learning clerkships.

A preliminary quantitative study conducted among the third-, fourth-, and fifth-year B.Pharm. students of the study's pharmacy school reported that these students had positive attitudes towards pharmaceutical care (Onah et al., 2018). However, this study did not provide rich and detailed accounts of students' experiences of clerkship. A further study was needed to assess the students' clerkship experiences qualitatively.

The study aim was to assess undergraduate final-year B.Pharm. students' preparedness, expectations, and experiences of hospital-based CPC programmes. 
Table I: The B.Pharm. curriculum of the University of Maiduguri showing experiential-learning courses

\begin{tabular}{|c|c|c|c|c|}
\hline First-year & Second-year & Third-year & Fourth-year & Fifth-year \\
\hline $\begin{array}{l}\text { Chemistry } \\
\text { (CHM 101, 103, 111, 121, } \\
\text { 113) }\end{array}$ & $\begin{array}{l}\text { Pharmacognosy } \\
\text { (PCG 201, 202) }\end{array}$ & $\begin{array}{l}\text { Pharmacognosy } \\
\text { (PCG 301, 302) }\end{array}$ & $\begin{array}{l}\text { Pharmacognosy } \\
\text { (PCG 401, 402) }\end{array}$ & $\begin{array}{l}\text { Pharmacognosy } \\
\text { (PCG 501, 502) }\end{array}$ \\
\hline $\begin{array}{l}\text { Biology } \\
\text { (BIO 101, 102, 104) }\end{array}$ & $\begin{array}{l}\text { Pharmaceutical } \\
\text { chemistry } \\
\text { (PCH 201, 202) }\end{array}$ & $\begin{array}{l}\text { Pharmaceutical } \\
\text { chemistry } \\
\text { (PCH 301, 303) }\end{array}$ & $\begin{array}{l}\text { Pharmaceutical } \\
\text { chemistry } \\
\text { (PCH 401, 402, 403, 404) }\end{array}$ & $\begin{array}{l}\text { Pharmaceutical } \\
\text { chemistry } \\
\text { (PCH 501, 502, } 503\end{array}$ \\
\hline $\begin{array}{l}\text { Physics } \\
\text { (PHY 101, 102, 103, 104, 161, } \\
\text { 162) }\end{array}$ & $\begin{array}{l}\text { Pharmaceutics and } \\
\text { pharmaceutical microbiology } \\
\text { (PCT 201, 202, 203, 204, 206) }\end{array}$ & $\begin{array}{l}\text { Pharmaceutics and } \\
\text { pharmaceutical microbiology } \\
\text { (PCT 301, 302, 303, 304, 305, } \\
\text { 307, 309) }\end{array}$ & $\begin{array}{l}\text { Pharmaceutics and } \\
\text { pharmaceutical microbiology } \\
\text { (PCT 401, 402, 403, 404, 405) }\end{array}$ & $\begin{array}{l}\text { Pharmaceutics and } \\
\text { pharmaceutical microbiology } \\
\text { (PCT 501, 502, 503, 504, 505, } \\
507 \text { ) }\end{array}$ \\
\hline $\begin{array}{l}\text { Mathematics } \\
\text { (MTH 101, 102) }\end{array}$ & $\begin{array}{l}\text { Clinical pharmacy and } \\
\text { pharmacy practice } \\
\text { (PCP 201) }\end{array}$ & $\begin{array}{l}\text { Pharmacology } \\
\text { (PCL 301, 302, 303, 304, 305, } \\
306,307,308)\end{array}$ & $\begin{array}{l}\text { Pharmacology } \\
\text { (PCL 401, 402, 403, 404, 405, } \\
406 \text { ) }\end{array}$ & $\begin{array}{l}\text { Pharmacology } \\
\text { (PCL 501, 502, 503) }\end{array}$ \\
\hline $\begin{array}{l}\text { Statistics } \\
\text { (STAT 101) }\end{array}$ & $\begin{array}{l}\text { Anatomy } \\
\text { (ANA 211, 213, 221, 222) }\end{array}$ & $\begin{array}{l}\text { Clinical pharmacy and } \\
\text { pharmacy practice } \\
\text { (PCP 301, 302, 303, 305) }\end{array}$ & $\begin{array}{l}\text { Clinical pharmacy and } \\
\text { pharmacy practice } \\
\text { (PCP 401, 402, 403, 404, 405, } \\
406,408 \text { ) }\end{array}$ & $\begin{array}{l}\text { Clinical pharmacy and } \\
\text { pharmacy practice } \\
\text { (PCP 501, 502**, 503, 504, } \\
505,507 \text { ) }\end{array}$ \\
\hline $\begin{array}{l}\text { General studies } \\
\text { (GST 111, 112, 113, 122, 123) }\end{array}$ & $\begin{array}{l}\text { Physiology } \\
\text { (S-PHY 201, 202, 203, 204) }\end{array}$ & $\begin{array}{l}\text { Externship I } \\
\text { (SIWES 399*) }\end{array}$ & $\begin{array}{l}\text { Externship II } \\
\text { (SIWES 499*) }\end{array}$ & Research project \\
\hline & $\begin{array}{l}\text { Biochemistry (BCHM 201, } \\
\text { 202, 203, 204) } \\
\text { General studies } \\
\text { (GST 211, 212, 221, 231, } \\
224 \text { ) }\end{array}$ & & & \\
\hline
\end{tabular}

*Introductory experiential-learning in the hospital pharmacy and community pharmacy

**Clinical pharmacy clerkship in the hospital wards

\section{Methods}

\section{Study design \& setting}

This was a pre-post, qualitative study involving focus groups. Focus groups enhance researchers' ability to gain access to participants' attitudes, perceptions, and experiences (Williams \& Katz, 2001; Krueger \& Casey, 2002; Levers, 2006). Consistent with the study objective, grounded theory was used to explore and understand students' experiences. Grounded theory helps researchers to comprehend peoples' experiences in a rigorous and detailed way (Ryan \& Bernard, 2000). This study was conducted in a room the participants were familiar with at the Faculty of Pharmacy, University of Maiduguri, Nigeria. This choice helped to create a conducive and relaxed environment that put the participants at ease for open discussion.

\section{Participants \& focus groups}

All 63 B.Pharm. final-year students of the 2019 academic year (October 2018 to June 2019) who enrolled for the CPC course were purposively selected and participated in the study. Nine groups of seven students each formed the focus groups for the study. The first author was the course coordinator and, therefore, took the role of the facilitator to keep the discussion focused on the specific topic and to facilitate open discussion. The facilitator had built rapport with the participants during the course of the programme to facilitate open disclosures. Three questions each for pre- and post-CPC, adapted from a previous similar study from a South African pharmacy school, were used to direct the discussions (see Appendix) (McCartney \& Boschmans, 2018). This is because this pharmacy school has a CPC course similar to the one in this study in terms of design, content, structure, and implementation.

\section{Ethical consideration}

Ethical approval was granted by the Faculty of Pharmacy Research Review Committee, University of Maiduguri. The authors obtained written informed consent of the participants before enrolment in the study, no incentives were offered to the participants, and participation was voluntary. Participants were assured of the anonymity of their identity and the confidentiality of the information provided. 


\section{Data collection}

Data were collected prior to the commencement of, and again on completion of, the CPC through focus group discussions (FGDs). The pre- and post-CPC FGDs took place on 2nd July 2019 and 23rd September 2019, respectively. On both occasions, the students were briefed on the study objectives. The FGDs continued until data saturation was attained (when sessions appeared redundant and additional data collection generated no new information). All discussions were audio-recorded, and a research assistant noted the order of the discussion and the key points.

\section{Data analysis}

The audio recordings were transcribed verbatim manually by the first author for thematic analysis, and the coauthors verified the transcripts by checking them against the audio recordings for consistency and accuracy. The data were analysed using directed qualitative content analysis (Hsieh \& Shannon, 2005). The transcripts were first read repeatedly before the thematic coding of the data by the first author and confirmed independently by the other two authors who also resolved any discrepancies. The recurrent and dominant themes were identified through a process of inductive reasoning. All the themes identified from the discussions were then placed in the appropriate categories. Participants' quotes were used to illustrate themes and enhance result clarity. Each participant and focus group were identified numerically (e.g. Participant one as P1, and Focus group one as F1) in the transcription.

Table II: Demographic information of the participants

\begin{tabular}{lll}
\hline Variable & Frequency & Percent \\
\hline Gender & 23 & 36.5 \\
Female & 40 & 63.5 \\
Male & & \\
Age group (years) & 50 & 79.4 \\
$22-26$ & 10 & 15.9 \\
$27-31$ & 3 & 4.7 \\
$\geq 32$ & &
\end{tabular}

\section{Results}

The mean age of the participants was $25.5 \pm 2.4$ years, while the age range was 22 - 35 years. Table II shows the detailed demographic characteristics of the study population.

The results are presented based on the emerging themes identified during analysis. The results are from the Pre-CPC data and from the students' retrospective perspective on completion of the hospital-based experiential-learning programme (Post-CPC). All direct quotations from the transcripts are italicised, and the timing of the focus group is identified using Pre- or Post-CPC.

\section{Theme one: Level of preparedness and hospital environment}

The students had positive expectations prior to commencement of the CPC. They longed for the opportunity to apply their knowledge in the hospital settings but also expressed anxiety about going to a new environment. At the start of the clerkship, most of the students felt prepared and ready to face any challenge that would arise headlong:

I'm really prepared because I have been waiting for this. I thought we would have kick-started in the first week of resumption...'

[P3: F1: Pre-CPC]

'This is something I'm excited about because we have gone through pharmacotherapeutics courses from fourth- to fifth-year.'

[P5: F2: Pre-CPC]

I'm prepared to learn, but my greatest challenge is how to start. I am afraid because it's a new environment, when I am doing something for the first time, I usually have this tension.'

[P1: F5: Pre-CPC]

'I am prepared to face the challenges ahead, in terms of the superiority complex of the doctors.'

[P4: F6: Pre- CPC]

At the end of the ten-week CPC, most students reported that they were not confident at the beginning of the programme because the hospital ward was an alien environment to them, that they had shallow knowledge of diagnosis, and that they were told by their predecessors that doctors are not friendly with pharmacy students in the ward. Nevertheless, they admitted that their confidence grew over time when they found out that the pictures painted about doctors by their predecessors were not entirely correct, although many expressed frustration as they had difficulties reading the doctors' handwriting and understanding the prevailing local dialect (Kanuri) used by patients which most doctors used to communicate with these patients: 
'My confidence level was very low because the environment was new to me, and also that was the first time I was putting my theoretical knowledge into clinical practice.'

[P7: F9: Post-CPC]

'For me, confidence grew over time as we became familiar with the ward environment...'

[P1: F1: Post-CPC]

'I was not all that confident because I have shallow knowledge of diagnosis and most of their questions in the ward were on diagnosis and a little question that came from drugs were based on the practical drugs (drugs they are using in the hospital) and we have more knowledge of theoretical drugs and the mechanism of actions.'

[P6: F3: Post-CPC]

'In most cases, I found it difficult to read the doctor's documentation due to bad handwriting which I pointed out to one of them who told me that they were trained to write fast.'

[P2: F4: Post-CPC]

'Doctors communicating with most patients in Kanuri were a source of frustration to me because I don't understand Kanuri.'

[P6: F4: Post-CPC]

\section{Theme two: Integration of knowledge and application to patient care}

Prior to the commencement of the $\mathrm{CPC}$, most of the participants expressed that the exercise would allow them to apply the knowledge they had gained in the classroom over the years to patient care:

'This is the right time for us to apply all the knowledge we have gained particularly from Clinical Pharmacy Department into real practice. We are really excited.'

[P3: F1: Pre-CPC]

'I expect to know how to apply all the knowledge that we had gained from the class, provide pharmaceutical care to our patients. It will afford me with an opportunity to interact with patients and learn how to involve other healthcare professionals in managing patients. It will be a very helpful exercise.'

[P6: F9: Pre-CPC]

Furthermore, the mandatory externship programmes (Students Industrial Work Experience Scheme (SIWES)) done in the community pharmacies and hospitals during the third- and fourth-year of the pharmacy programme were perceived to have prepared the students for the patient-centred care to some extent:
'Counselling patients on their medications during my externship in the community pharmacy helped me to build confidence to talk to patients.'

[P1: F7: Pre-CPC]

'I think externship has prepared me for the ward round because my first experience in the hospital pharmacy trying to correlate the drugs I learned in the third-year was difficult for me. I was better after it exposed me to such drug; seeing how they come...'

[P2: F3: Pre-CPC]

Contrary to the views of most of the participants, one participant expressed frustration with the lack of direct involvement with patient care during his externship programme in the hospital:

'I think this externship has helped in a way but has not helped so much in getting prepared for the ward round because in the hospitals where I did mine, I didn't go for the ward rounds.'

[P5: F8: Pre-CPC]

Most of the students expressed mixed feelings while reporting how their expectations were met in terms of clinical knowledge:

'My expectation after the ten-weeks is to be at a different level in terms of clinical knowledge and then build confidence in addressing different disease conditions without fear.'

[P7: F8: Pre-CPC]

'My expectation was not met; because it was a function of time and we spent just six days in a unit, so what we had started learning in a particular unit was usually truncated...'

[P3: F1: Post-CPC]

'My expectations were not met, because my group didn't rotate to endocrinology and neuropsychiatry units. I am concerned about missing these two specialties...'

[P5: F1: Post-CPC]

'I am expecting to see drugs used in managing various disease conditions in the ward.'

[P1: F9: Pre-CPC]

I had some of my expectations met because I saw several disease conditions and how drugs were prescribed to handle such diseases practically, others were not met...'

[P7: F3: Post-CPC] 


\section{Theme three: Inter-professional relationships and professional identity}

Before the CPC started, most students showed keen interest and looked forward to working with doctors and nurses in the ward for the first time. Also, they saw it as an opportunity to mingle with medical students as their cohealthcare professional students. But their perception after getting into the ward was different:

'I expect to see the role of the pharmacist in the healthcare system, how he addresses drug interactions and adverse effect.'

[P3: F8: Pre-CPC]

'I expect to witness the relationship between pharmacists and other health professionals in the hospital.'

[P5: F7: Pre-CPC]

'Disappointedly, pharmacists were absent from the wards and some doctors did not want to talk to us...'

[P3: F3: Post-CPC]

'I was told that we will be together with medical students in the ward, I was excited about this because it is going to provide a rare opportunity to learn from each other.'

[P7: F5: Pre-CPC]

'We were seen as intruders and not as a part of the healthcare team......we were not usually allowed to mingle with the medical students in the ward, we were always segregated.'

[P1: F4: Post-CPC]

'To my surprise, medical students were even calling us bulking agents.'

[P4: F6: Post-CPC]

On completion of the programme, most students described how they found the comments of some doctors at the teaching hospital antagonistic, which appeared to downgrade the pharmacist's role in the healthcare team:

'Most doctors usually said that you pharmacy students come to the ward to fish out our problems and not drug therapy problems.'

[P5: F1: Post-CPC]

'Some doctors were calling us salespersons...'

[P3: F1: Post-CPC]

'The doctors and medical students were telling us that we don't belong to the ward with an impression that we are coming to the ward to dominate them...'

[P1: F5: Post-CPC]
Contrary to the views of many about the antagonistic comments of some doctors, one student had this to say:

'I never heard doctors insult us, they never insulted us 'gaskiya' (Hausa word for truth)..... They asked us questions and also gave us the chance to ask questions too. The problem is with us, because we don't read.'

[P6: F2: Post-CPC]

\section{Theme four: Challenges and recommendations for clinical pharmacy clerkship}

Participants identified some barriers against successful hospital-based CPC programmes such as lack of interprofessional relationships, insufficient time, lack of knowledge of current medications used in the hospitals, lack of preceptors and absence of university tutors to guide them in the ward, and harshness of the university tutors during the preview/review section.

'Doctors didn't appreciate our presence...'

[P7: F1: Post-CPC]

'My challenge was insufficient time allocated to the ward rounds; we could not learn all the diseases taught in the classroom.'

[P1:F3: Post-CPC]

'Doing ward round in a single semester was a challenge because it was not enough for any meaningful learning to take place.'

[P5: F3: Post-CPC]

'Our lecturers were not following us to the ward.'

[P7: F4: Post-CPC]

'After our presentations during preview/review section, our tutors gave us no words of encouragement...'

[P4: F3: Post-CPC]

Participants having identified challenges made recommendations to help improve the programme:

'Clinical pharmacists working in the hospital should take part in the ward round for doctors to see the contributions of pharmacists that will make them to appreciate pharmacy students, when they come for the ward rounds.'

[P2: F2: Post-CPC]

'Adoption of preceptor system where students are assigned to pharmacists that will guide them in the ward...'

[P1: F7: Post-CPC]

'This programme should be split into junior and senior postings (one month in fourth-year and two months in the final-year)...'

[P7: F9: Post-CPC] 
'Our university tutors should make a little commendation on the effort of the students while things done wrong should be corrected passionately during the preview/ review section.'

[P4: F1: Post-CPC]

\section{Discussion}

To the authors' knowledge, the present study is the first qualitative pre-post study to evaluate undergraduate finalyear pharmacy students' clinical experience of the hospital-based experiential-learning programme in Nigeria.

In Nigeria, clinical pharmacists do not take part in the ward round in most of the public and private hospitals. The level of participation of clinical pharmacists in the ward round in both public and private hospitals is generally poor (ranging from sub-optimal participation in some cases to non-existence in the majority of others) (Okoro \& Auwal, 2015). The most outstanding reasons may be grouped into factors relating to not well-defined clinical pharmacy practice in health institutions, inadequate clinical pharmacists, as well as problems relating to inter-professional issues and difficult protocols that are not easily overcome (Anyika \& Alade, 2009). These notwithstanding, the authors' finding in the present study show that the absence of pharmacists in the ward to supervise and guide pharmacy students constituted a major challenge to the CPC programme, particularly at the study zone.

In Maiduguri, no pharmacist takes part in the ward round, so pharmacy students are placed under the supervision of doctors. The findings are in line with what is reported in Iran and South Africa (Eslami et al., 2014; McCartney \& Boschmans, 2018). Although there are satellite pharmacies attached to most units of the hospital, their operations focus on medication supply rather than pharmaceutical care or clinical services. It is, however, noteworthy that the authors' ward round is a semistructured one, involving a preview section that lasts for one and half hours, where cases encountered in the ward during rounds with doctors are exhaustively discussed with students by the university tutors. Despite this alternative way of making up for the absence of pharmacists in the ward, occasioned by un-surmounted protocols, some students still perceived that they go to the wards unsupervised and unguided by pharmacists. They reported that the ward round added little value for learning clinical skills and complained that they were on their own in the ward which was perceived as a waste of time. Conversely, in Iran, in spite of the absence of clinical pharmacists in the hospital ward to supervise pharmacy students on CPC programmes, most of these students reported that resident doctors were eager to teach and guide them throughout the course duration (Eslami et al., 2014).

With this approach, the clinical knowledge and practice of the students may not be appropriately supervised (Moczygemba et al., 2011; Rathbun et al., 2012). The authors' study suggested that some pharmacy students may have lacked knowledge of the clinical roles of the clinical pharmacist. However, a previous study done in one of the host hospitals reported positive perceptions among doctors about the participation of clinical pharma-cists in the ward round (Okoro \& Auwal, 2015). It is the university tutors' perception that if students failed to learn clinical skills despite the intensive coaching during the review of cases and to apply this during the ward round with doctors, then they have a poor learning attitude (Bassaw \& Naraynsingh, 2011). This perception not withstanding, if clinical pharmacists continue to be absent in the hospital wards and the obstacles that keep them away from the wards in some of the tertiary hospitals in Nigeria are not addressed, this may have negative repercussions to the attainment of the objectives of the newly approved Pharm.D. programme.

Despite undergraduate pharmacy curricula modifications to include clinical services and some basic pharmaceutical care components in some pharmacy schools, the muchdesired outcomes are yet to be achieved (Auta, StricklandHodge, \& Maz, 2016). Many Nigerian hospitals still lack clinically-oriented pharmacists due to a lack of specialisation and clinical career framework (Auta, StricklandHodge \& Maz, 2016). As a result, the pharmacy students in the authors' study identified a gap and had no insight into the pharmacist's roles as a member of the healthcare team on completion of the programme. Without appropriate support for clinical pharmacists to be present on wards to supervise and engage with students, changes from the B.Pharm. to the Pharm.D. programme will represent a mere change of nomenclature. Hence, clinical pharmacists' participation in ward rounds, part-time engagement of the clinical tutors from the university by the hospital management, and integrating them into the ward round team are recommended.

B.Pharm. students in Nigeria are exposed to the ward for the first time in their final-year, and this often creates fear and anxiety in them because of the unfamiliarity of the hospital environment (Auta, Strickland-Hodge \& Maz, 2016). Notwithstanding this observation, most students were able to regain confidence as the programme progressed. However, the majority of the students 
expressed that the externship programme (SIWES) in the community pharmacy setting prepared them to some extent for the hospital-based experiential-learning exercise. Most students described that it provided them with opportunities to interact with patients and helped to boost their confidence in communicating with patients. This was contrary to the finding in South Africa where students had little or no opportunity to interact with patients during their externship in a community pharmacy (McCartney \& Boschmans, 2018). Practice variations among countries could account for this difference. The perspectives of the tutors are that most students were illprepared for the ward round programme, and this may have contributed to their initial concern about a lack of the desired confidence in the midst of other healthcare profession students (McCartney \& Boschmans, 2018).

Another notable finding was the lack of inter-professional relationships. Prior to the commencement of the CPC, most students had expectations of building an interprofessional relationship with both doctors and medical students, however, they were disappointed by their experiences. The students expressed their expectation and frustrations during the discussion. This finding is a serious concern that needs to be addressed urgently in order for the Nigerian healthcare professionals' education to be in tune with global best practice of an increasing collaboration of healthcare providers to optimise patients' health (Auta, Strickland-Hodge \& Maz, 2016). In the US, both pharmacy students and medical students are required to participate in the inter-professional experiential education (IPE) programme together, to fulfil accreditation standards for both pharmacy and medical education (Nwaesei et al., 2019). This programme provides these students with opportunities to learn about each other's training and roles on the team and to engage in peer teaching. Contrary to the authors' finding, it has been reported in the US that most pharmacy and medical students appeared to better perceive the value of working together with other healthcare professions students on enhancing their knowledge and ability to work on an interdisciplinary team upon graduation (Nwaesei et al., 2019).

Tackling increasingly varied and complex health problems requires a multidisciplinary collaboration in which pharmacists, with expertise in drug therapy, can play a vital role in providing valuable contributions to patient care (Carter et al., 2009; Bryant et al., 2010). The authors' experience in the study area is that some health professionals erroneously perceive 'owning the patients' and pharmacists are viewed as intruders in the area of patient care, thereby jeopardising the much desired inter- professional relationship the clinical pharmacy clerkship was set to achieve. This has generated hostility towards pharmacists aiming at performing pharmaceutical care services or pharmacy students aiming at learning pharmaceutical care skills whenever they are sighted in the wards. Although some of the Nigerian hospitals have broken this barrier, the authors' findings indicate there is still some way to go (Anyika \& Alade, 2009; Suleiman \& Onaneye, 2011).

In contrast to the authors' findings, doctors in Iran are very keen to teach and guide pharmacy students on hospitalbased experiential learning in the absence of pharmacists in the wards (Eslami et al., 2014). Rare interactions and poor inter-professional relationships between doctors and pharmacists in the hospital setting are a direct consequence of a lack of experience of doctors with clinical pharmacists. Therefore, Nigerian pharmacists need to work more closely with doctors, thereby providing them with an opportunity to observe pharmacists' clinical capabilities first-hand, and they should also make doctors more confident towards the roles of pharmacists in the healthcare team (Zillich et al., 2004).

The students identified the shortness of the duration of their clerkship and the combination of CPC with other course work from other departments in the school as the major factors militating against the success of the programme. In agreement with the authors' finding, an earlier study conducted in China also reported shortness of the duration of clerkship as a barrier to a meaningful clerkship experience (Lai et al., 2010). A key strength of the new Pharm.D. curriculum identified by this study is that students' exposure to ward environments is no longer limited. Pharm.D. students are exposed to the ward both in the fifth- and sixth- (final-)year of the programme. On the other hand, the disadvantage is that no single semester or session is dedicated to CPC as obtained in Ethiopia, Saudi Arabia, and the US (Melaku et al., 2016; Alkatheri et al., 2019; UW, 2020). This is a serious concern for the students and needs to be addressed urgently.

\section{Limitations}

The limitations of the study were capturing the views of students from one locality of the country which may not be generalised and the failure to hear the view of the programme designers. Further, the inability to conduct completed participant checking to confirm their interpretation of the data was also a limitation. 


\section{Conclusions}

This study shows that undergraduate final-year pharmacy students exhibited a high level of preparedness and expectations prior to the commencement of the CPC. They also had unsatisfactory experiences during the CPC due to various challenges and unmet expectations, mainly in terms of inter-professional relationships and the role of pharmacists in the healthcare team.

Pharmacy educators in Nigeria need to take urgent steps to ensure that pharmacy role models participate in the ward rounds if the required learning objectives of the hospital-based CPC programme are to be achieved. Taking rare contact among healthcare professionals into account, inter-professional experiential education between pharmacy and medical students is highly recommended for consideration within Nigerian undergraduate and postgraduate medical and clinical pharmacy educational programmes.

\section{Acknowledgments}

The authors appreciate all the final-year pharmacy students of the 2019 academic year of the University of Maiduguri, Nigeria for taking part in the study.

\section{Funding}

The research was funded by the authors.

\section{Conflicts of Interest}

The authors declare no conflicts of interest.

\section{References}

Abbas, A. (2014). Evidence Based Improvements in Clinical Pharmacy Clerkship Program in Undergraduate Pharmacy Education: The Evidence Based Improvement (EBI) Initiative. Pharmacy, 2(4), 270-275. https://doi.org/10.3390/pharmacy2040270

Abdu-Aguye, S.N., Yusuf, H., Agbale, E.O., Auwal, F.I., \& Ma'aji, H.U. (2019). Connections between classroom theory and real world practice: Exploring the perspectives of undergraduate students at a Nigerian faculty of pharmacy. Pharmacy Education, 19(1), 185-189

ACPE (Accreditation Council for Pharmacy Education). (2016). Accreditation Standards and Key Elements for the Professional Program in Pharmacy Leading to the Doctor of Pharmacy Degree (online). Available at: https://www.acpe-accredit.org/pdf/ Standards2016FINAL.pdf
Alkatheri, A.M., Albekairy, A.M., Khalidi, N., Phelps, S.J., Gourley, D.R., Al Jeraisy, M., \& Qandil, A.M. (2019). Implementation of an ACPE-Accredited PharmD curriculum at a Saudi College of Pharmacy. American Journal of Pharmaceutical Education, 83(9), Article 6237. https://doi.org/10.5688/ajpe6237

Al-Worafi, Y.M. (2014). The challenges of pharmacy education in Yemen. American Journal of Pharmaceutical Education, 78(8), Article 146. https://doi.org/10.5688/aipe788146

Anyika, E.N., \& Alade, T.B. (2009). Evaluation of Pharmacists' Participation in Post-admission ward rounds in a tertiary hospital in South-west Nigeria. Nigerian Quarterly Journal of Hospital Medicine, 19(3), 151-154. https://doi.org/10.4314/ nqjhm.v19i3.54498

Asiri, Y.A. (2011). Emerging frontiers of pharmacy education in Saudi Arabia: The metamorphosis in the last fifty years. Saudi Pharmaceutical Journal, 19(1). https://doi.org/10.1016/ j.jsps.2010.10.006

Auta, A., Strickland-Hodge, B., \& Maz, J. (2016). Challenges to clinical pharmacy practice in Nigerian hospitals: a qualitative exploration of stakeholders' views. Journal of Evaluation in Clinical Practice, 22(5), 699-706. https://doi.org/10.1111/jep.12520

Bassaw, B.E., \& Naraynsingh, V. (2011). Ward-Rounds: roles in clinical teaching and learning in contemporary medicine. West Indian Medical Journal, 60(6), 37-43

Bhagavathula, A.S., Sarkar, B.R., \& Patel, I. (2014). Clinical pharmacy practice in developing countries: Focus on India and Pakistan. Archives of Pharmacy Practice, 5(2), 91-94. https:// doi.org/10.4103/2045-080X.132661

Bryant, L., Coster, G., \& McCormick, R. (2010). General practitioner perceptions of clinical medication reviews undertaken by community pharmacists. Journal of Primary Health Care, 2(3), 225-233. https://doi.org/10.1071/HC10225

Carter, B.L., Rogers, M., Daly, J., Zheng, S., \& James, P.A. (2009). The potency of team-based care interventions for hypertension: a meta-analysis. Archives of Internal Medicine, 169(19),1748-1755. https://doi.org/10.1001/archinternmed.2009.316

Carter, B.L. (2016). Evolution of Clinical Pharmacy in the USA and Future Directions for Patient Care. Drugs \& Aging, 33(3), 169-177. https://doi.org/10.1007/s40266-016-0349-2

CPU (China Pharmaceutical University). (2015). Office of Academic Affairs (online). Available at: http://www.cpu.edu.cn/4216/list.htm

Eslami, K., Khezrian, M., Rezaei, M., \& Kouti, L. (2014). Offering Clinical Pharmacy Clerkship in Hospital for Pharmacy Student: A Successful Cooperation between Medical and Pharmacy Schools. Journal of Pharmaceutical Care, 2(1), 32-36

Falade, J. (2011). How UK universities are contributing to global spread of pharmacy practice. Pharmaceutical Journal, 286(7644), 304-305

Hsieh, H., \& Shannon, S. (2005). Three Approaches to Qualitative Content Analysis. Qualitative Health Research, 15(9), 1277-1288. https://doi.org/10.1177/1049732305276687 
Karim, Z., \& Noott, A. (2011). An overview of pharmacy practice in Canada. Tomorrow's Pharmacist

Katajavuori, N., Hakkarainen, K., Kuosa, T., Airaksinen, M., Hirvonen, J., \& Holm, Y. (2009). Curriculum reform in Finnish pharmacy education. American Journal of Pharmaceutical Education, 73(8), Article 151. https://doi.org/10.5688/aj7308151

KFU (King Faisal University). (2014). College of Clinical Pharmacy, Faculty Handbook 2013-14. Al-Ahsa: King Faisal University

Krueger, R. (1988). Focus groups: a practical guide for applied research. Thousand Oaks, California, Sage Publications

Lai, S., Yang, F., Li, M.Y., \& Wu, H.W. (2010). Curriculum setting of clinical pharmacy education and clinical practice in America and Britain. China Pharmacy, 29, 2706-2709

Lam, A. (2018). Clinical Pharmacy in Australia and the UK: How close are they now and are they set for closer collaboration? Journal of Pharmacy Management, 34(3), 93-100

Levers, L. (2006). Focus groups and related rapid assessment methods: identifying psychological HIV/AIDS interventions in Botswana. In C.T. Fischer (Ed.), Qualitative Research Methods for Psychologists (pp. 377-410). Elsevier, New York. https://doi.org/ 10.1016/B978-012088470-4/50016-8

McCartney, J., \& Boschmans, S. (2018). South African pharmacy student perspectives of a hospital-based experiential learning programme. Pharmacy Education, 18(1), 29-40

Melaku, T., Bhagavathula, A.S., Getaye, Y., Admasu, S., \& Alkalmi, R. (2016). Perceptions of pharmacy clerkship students and clinical preceptors regarding preceptors' teaching behaviors at Gondar University in Ethiopia. Journal of Educational Evaluation for Health Profession, 13(9). https://doi.org/10.3352/jeehp.2016.13.9

Meng, X.M., Wan, C.L., Li, H.D., Wang, H., \& Li, J. (2017). The comparison of higher education in clinical pharmacy between China and the United States. Anhui Medical and Pharmaceutical Journal, 21(5), 966-969

Moczygemba, L.R., Goode, J.V., Silvester, J.A., \& Matzke, G.R. (2012). Pharmacy practice in Virginia in 2011. Annals of Pharmacotherapy, 46(4), 13-26. https://doi.org/10.1345/ aph.10802

Moustafa, M.A.A. (2014). Towards Pharmaceutical Care Services in Saudi Arabia, Personal Experience. Journal of Pharmaceutical Care and Health Systems, 1(4).

NUC (National University Commission). (2018). Benchmark Minimum Academic Standards for Undergraduate Programmes in Nigerian Universities, Pharmaceutical Sciences. Abuja: National Universities Commission

Nwaesei, A.S., Jacob, B.C., Peasah, S.K., Perkins, J.J., \& Hogan, M. (2019). A structured approach to intentional interprofessional experiential education at a non-academic community hospital. American Journal of Pharmaceutical Education, 83(9), Article 7365. https://doi.org/10.5688/ajpe7365

Okoro, R.N., \& Auwal, M.A. (2015). Hospital pharmacists' participation in multidisciplinary ward rounds: physicians' perceptions and attitudes. British Journal of Pharmaceutical Research, 5(5), 319-327. https://doi.org/10.9734/BJPR/ 2015/12849
Onah, P.O., Siyaka, L., Kaigamma, A., \& Ahmed, A. (2018). Attitudes towards Pharmaceutical care among Pharmacy Students in a Nigerian University. Nigerian Journal of Pharmaceutical and Biomedical Research, 3(2), 176-180

Owen, S., \& Stupans, I. (2009). Australian pharmacy programme experiential placements: comprehensive planning for assessment and evaluation. Assessment \& Evaluation in Higher Education, 34(5), 579-594. https://doi.org/10.1080/02602930802255154

Rathbun, R.C., Hester, E.K., Arnold, L.M., Chung, A.M., Dunn, S.P., Harinstein, L.M., Leber, M., Murphy, J.A., Schonder, K.S., Wilhelm, S.M., \& Smilie, K.B. (2012). Importance of direct patient care in advanced pharmacy practice experiences. The Journal of Human Pharmacology and Drug Therapy,, 32(4), 88-97. https://doi.org/ 10.1002/i.1875-9114.2012.01110.x

Ryan, G., \& Benard, H. (2000). Data management and analysis methods. In: N.K. Denzin, \& Y.S. Lincoln (Eds), Handbook of Qualitative Research (2nd Edn) (pp. 769-802). Sage Publications, London

Sosabowski, M.H., \& Gard, P.R. (2008). Pharmacy education in the United Kingdom. American Journal of Pharmacy Education, 72(6), Article 130. https://doi.org/10.5688/aj7206130

Suleiman, I.A., \& Onaneye, O. (2011). Pharmaceutical care implementation: a survey of attitude, perception and practice of pharmacists in Ogun State, South-Western Nigeria. International Journal of Health Research, 4(2), 91-97

Tsega, B., Bhagavathula, A.S., Sarkar, B.R., Melaku, T., \& Shewamene, Z. (2015). Impact of clerkship attachments on students' attitude toward pharmaceutical care in Ethiopia. Advances in Medical Education and Practice, 6, 385-391. https:// doi.org/10.2147/AMEP.S80802

Unimaid (University of Maiduguri). (2016). Faculty of Pharmacy students' prospectus. Abuja: Mitchel Publisher

UW (University of Washington). (2020). School of Pharmacy. Doctor of pharmacy (PharmD) curriculum (online). Available at: http://sop.washington.edu/pharmacyd/curriculum/

Williams, A., \& Katz, L. (2001). The use of focus group methodology in education: some theoretical and practical considerations. International Electronic Journal for Leadership in Learning, 5(3)

Zillich, A.J., McDonough, R.P., Carter, B.L., \& Doucette, W.R. (2004). Influential characteristics of physician/pharmacist collaborative relationships. Annals of Pharmacotherapy, 38(5), 764-770. https:// doi.org/10.1345/aph.1D419 